\title{
ABORDAJE ESPACIAL: CIMA Y LADERA DEL POBLADO INTERMEDIO TARDÍO EL CARMEN 1 (VALLE DE SANTA MARÍA, NOROESTE ARGENTINO)
}

\author{
SPATIAL APPROACH: SUMMIT AND SLOPE OF LATE INTERMEDIATE EL \\ CARMEN 1 VILLAGE (SANTA MARÍA VALLEY, NORTHWESTERN ARGENTINA)
}

\author{
Violeta Cantarelli, ${ }^{1,2}$
}

\begin{abstract}
En este artículo se estudian dos sectores del poblado El Carmen 1 que está localizado sobre la falda occidental del Valle de Santa María (provincia de Tucumán, Argentina) y corresponde al periodo Intermedio Tardío. Los sectores que se analizan se ubican en topografías distintas: cima (Sector VI) y ladera (Sector XII). El objetivo de este trabajo consiste en realizar un análisis de percepción completo en ambos con el propósito de conocer la dinámica interna de sectores asentados sobre diferentes relieves. De esta manera, los resultados obtenidos permitirán profundizar el conocimiento sobre algunos aspectos en torno a la organización social del sitio, así como también ampliar la información sobre poblados tardíos con un patrón de asentamiento en altura y diferencia de elevación entre sectores. Los métodos adoptados siguen los lineamientos de la Arqueología del Paisaje y abarcan las técnicas utilizadas para el análisis formal y de percepción.
\end{abstract}

Palabras claves: análisis espacial, periodo Intermedio Tardío, El Carmen 1, Noroeste Argentino.

This article examines two sectors of the archaeological site El Carmen 1, a village located on the western side of the Santa María Valley (Tucumán Province, Argentina) and which corresponds to the Late Intermediate period. The sectors under study are located on different topographies: a summit (Sector VI) and a slope (Sector XII). The objective of this article is to carry out a complete perception analysis of both of the sectors in order to learn about their internal dynamics, as they are settled on different reliefs. The results obtained will enable to deepen the knowledge of the social organization of the sites, while increasing the information about Late Intermediate villages with a pattern of settlement in heights and with altitude differences between sectors. The methods that were used follow the guidelines of Landscape Archaeology, which involve the techniques available for formal and perception analysis.

Key words: Spatial analysis, Late Intermediate period, El Carmen 1, Northwestern Argentina.

Sobre la falda occidental del extenso Valle de Santa María (provincias de Catamarca, Tucumán y Salta) se registraron asentamientos tardíos de poblaciones pretéritas que estaban divididos en sectores jerárquicamente distintos. Mayormente se pudieron destacar poblados con emplazamientos en altura y diferencia de elevación entre sectores que no presentaban un trazado conglomerado ${ }^{1}$. En dirección sur-norte se distinguieron sitios como: Cerro Mendocino-Punta de Balasto, Rincón Chico, Fuerte Quemado, Quilmes, Tolombón y Pichao, entre otros (Figura 1).

La imagen de las sociedades tardías del Valle de Santa María se fundaba en extensos poblados localizados sobre topografías escarpadas. Sus habitantes habrían elegido terrenos irregulares buscando alcanzar beneficios defensivos. Mientras que en los espacios naturalmente no defendidos, con suaves relieves, habrían construido muros y murallas.

Dentro de un contexto de conflicto generalizado (Palma 1998; Sempé 1999; Tarragó 2000; entre otros), los poblados más fortificados habrían sido los más impenetrables. La tensión a nivel regional se habría manifestado en la intensificación económica y la concentración de personas en grandes centros poblados.

Frente a condiciones de creciente competencia y conflicto entre grupos, habría acaecido un proceso sociopolítico en el cual se manifestaron prácticas asociadas al ejercicio del poder, lo que habría provocado desigualdad y estratificación a partir del establecimiento de un segmento social que controlaba y administraba

\footnotetext{
${ }^{1}$ CONICET (Consejo Nacional de Investigaciones Científicas y Técnicas), Buenos Aires, Argentina. violecantarelli@gmail.com ${ }^{2}$ CCNAA (Centro de Ciencias Naturales, Ambientales y Antropológicas), Universidad Maimónides, Buenos Aires, Argentina.
} 


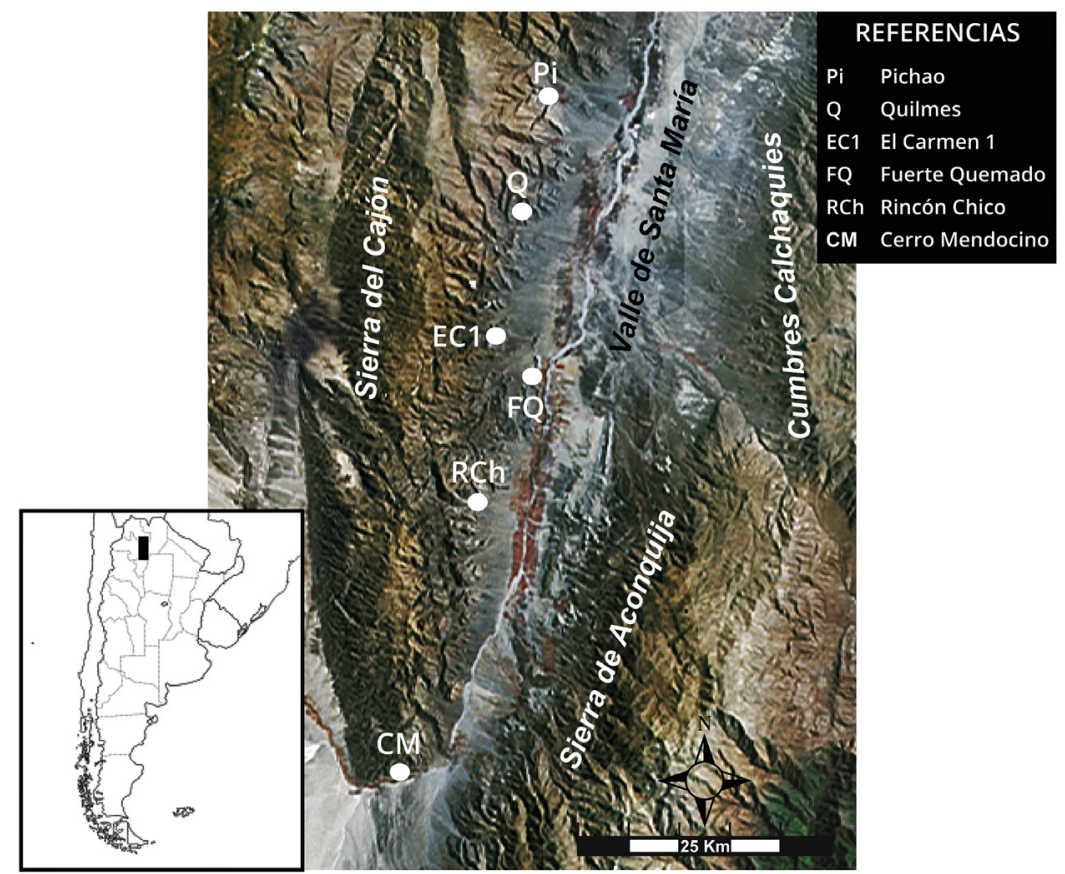

Figura 1. Asentamientos tardíos occidentales del Valle de Santa María (Tucumán y Catamarca) (Fuente: Atlas Argentina 2011, Instituto Geográfico Nacional 1: 500000).

Western late settlements of the Santa María Valley (Tucumán and Catamarca) (Source: Atlas Argentina 2011, National Geographic Institute 1: 500000).

las actividades, la producción y la distribución de los recursos.

El estudio de la arquitectura arqueológica permite una aproximación a la idiosincrasia de las poblaciones pretéritas. A diferencia de otras evidencias materiales, producto de fabricaciones individuales, las estructuras son el fruto de manufacturas y usos colectivos (Taboada 2005). La arquitectura impacta directamente en el espacio configurando un tipo de organización del comportamiento espacial. Es debido a esto que las construcciones se convierten en herramientas susceptibles de imponer ciertas normas y regular el acceso de las personas a recursos tales como: alimentos, protección, ceremonias, información, entre otros. Es decir, funcionan como herramientas sociales, en tanto que las personas pueden regular físicamente el comportamiento social. En este sentido, las estructuras manifiestan los efectos de las relaciones de poder y producen relaciones asimétricas (Nielsen 1995:56-59).

El estudio pormenorizado del modelo espacial producto de arquitectura erigida constituye una herramienta clave para decodificar el trasfondo social y simbólico (Hodder y Orton 1990). La arquitectura funciona como una herramienta más del sistema de saber-poder, el cual promueve mantener y reproducir el orden social (Foucault 1983) e impone a las personas esquemas espaciales que sancionan una determinada lógica social (Miller y Tilley 1984).
Los casos de estudios espaciales en la región andina (Vaquer y Nielsen 2011; Salminici 2015; Scaro 2019; entre otros) constituyen un gran aporte para la comprensión de dinámicas internas de los sitios arqueológicos porque pueden ser replicables y los resultados comparables. En muchos casos se analizaron minuciosamente los planos de los sitios y se evaluaron las posibilidades de movimientos y alcances visuales. Pero hasta el momento no se cuenta con análisis gamma de las unidades compuestas de los sectores residenciales en sitios vallistos. En este sentido, el objetivo de este trabajo es realizar un análisis de percepción completo en la cima del Sector VI y en la ladera del Sector XII del poblado El Carmen 1 con el propósito de conocer la dinámica interna de espacios topográficamente distintos. De esta manera, los resultados obtenidos del estudio del sitio contribuirán a profundizar el conocimiento sobre algunos aspectos en torno a la organización social en poblados tardíos que exhiban un patrón de asentamiento de emplazamiento en altura con diferencia de elevación entre sus sectores.

Para ello se utilizaron los lineamientos propuestos por la Arqueología del Paisaje, que aborda el estudio de la arquitectura arqueológica de manera integral, haciendo uso de la herramienta conceptual "zoom" (cf. Criado-Boado 1999:10). El abanico metodológico es amplio y abarca el análisis formal y de percepción de las construcciones arqueológicas. 
Con el objetivo de identificar patrones de espacialidad en los Sectores VI y XII, para poder correlacionarlos con la estructura socioeconómica y el aparato simbólico operado por la sociedad pretérita (Ayán Vila 2003), se emplearon técnicas y métodos analíticos de percepción como análisis de visualización, circulación y gamma.

\section{El Periodo Intermedio Tardío}

Las sociedades prehispánicas en el Noroeste Argentino comenzaron a experimentar una serie de cambios durante el periodo Intermedio Tardío (ca. 1000-1430 DC). Esta época se caracterizó por una complejidad social creciente (DeMarrais 2001; Nielsen 1996; Nielsen y Walker 1999; Tarragó 2000), una intensificación económica en un contexto de conflicto generalizado (Palma 1998; Sempé 1999; Tarragó 2000) y un aumento demográfico con mayor inversión en infraestructura productiva a escala desconocida respecto a los periodos previos.

A su vez, emergieron sociedades pujantes que controlaban y vigilaban amplios territorios desde los pukaras. En la sección meridional se destacaron las organizaciones de Sanagasta y Aimogasta en la provincia actual de La Rioja y de Angualasto en San Juan; más al norte se desenvolvieron las organizaciones de Calchaquí, Tastil, Yocavil y Belén en las actuales provincias de Salta, Tucumán y Catamarca; y en el sector septentrional, íntimamente asociado con el altiplano, se desarrollaron los núcleos políticos de Tilcara, Humahuaca, Yavi y Casabindo en la actual provincia de Jujuy (Tarragó 2000:2). Estos cambios han sido vinculados con el surgimiento de entidades sociopolíticas centralizadas, con características semejantes a las jefaturas (Earle 1987; Wright 1984), con distintos niveles en la jerarquía de asentamientos.

Fundamentalmente, se ha planteado la existencia de desigualdad y estratificación social a partir del establecimiento de una élite que controlaba las diversas actividades sociales y manejaba la producción, distribución y consumo de bienes confeccionados por artesanos especializados a su servicio. Su poder dentro de la sociedad se consolidaba a través del consumo de bienes o artefactos de prestigio con alto valor social (Palma 1998; Sempé 1999; Tarragó 2000; entre otros).

También se ha pensado al espacio en relación con la emergencia de grandes poblados en forma de conglomerados sobre mesetas y terrazas altas definidos como centros defensivos o fortalezas. La ocupación del territorio por parte de las poblaciones pretéritas se realizaba en función de un modelo de organización social jerarquizado donde la distancia social respecto al curaca se materializaba en la distancia física (Tarragó 1987). Es decir, que la espacialidad se constituyó como parte fundamental de la estructura social.
Recientemente, otros autores han propuesto modelos alternativos para comprender a las sociedades tardías del norte de Lípez en Bolivia (Nielsen 2001, 2006; Vaquer 2010; Vaquer y Nielsen 2011) y del Valle Calchaquí Norte en Argentina (Acuto 2007; Leibowicz 2007). Principalmente plantearon que no existía evidencia suficiente para sustentar la emergencia de grupos de elite que aglutinaban el poder durante el periodo Intermedio Tardío.

Acuto (2007) propuso repensar el Tardío en los valles Calchaquí Norte. Lejos de vincular al periodo con conceptos tales como: centralización política y desigualdad social, señaló la existencia de una integración comunal reflejada en la homogeneidad espacial y material.

Para el autor, la prevalencia de la integración comunal impidió y condicionó toda iniciativa que surgiese con fines exclusivamente monopolistas. La postura adoptada por el autor rechaza la existencia de poderes centralizados en competencia, pero contempla la posibilidad de que hayan existido situaciones de tensión y conflicto entre las personas con el objetivo de obtener preeminencia y jerarquía (Acuto 2007; Leibowicz 2007).

Porsuparte, Nielsen $(2001,2006)$ configuróun modelo corporativista para las sociedades tardías del norte de Lípez (Bolivia). El autor propuso la inexistencia de grupos aglutinadores de poder, en tanto que la población total se constituyó como la unidad de apropiación de recursos. Planteó que todos los grupos sociales se incluyeron en las tomas de decisiones para generar adhesión y comunión. Así como también, para lograr una organización política donde el poder fuera legitimado por toda la sociedad. Los líderes fueron los responsables de lograr la unidad social y su trabajo se fundó en hacer de sus intereses símbolos de pertenencia social.

Finalmente, Vaquer (2010) destacó que las sociedades tardías se encontraban inmersas dentro de un contexto sociopolítico caracterizado por un conflicto endémico en los Andes Meridionales. De modo que no rechazó la existencia del conflicto generalizado propuesto tradicionalmente para el periodo Intermedio Tardío en la arqueología del Noroeste Argentino.

\section{El Poblado El Carmen 1 y las Características Principales de los Sectores VI y XII}

El poblado El Carmen 1 se localiza en el centro-oeste del Valle de Santa María (Tucumán, Argentina) (Figura 1). Se emplaza en las quebradas El Carmen y El Carrizal sobre cimas, crestas, laderas y al pie de dos espolones dispuestos en dirección oeste-este (Figura 2). Fitogeográficamente se encuentra dentro de la provincia del Monte (Cabrera 1971). Su altitud varía aproximadamente entre los 1.850 y $2.450 \mathrm{msm}$ y principalmente se destacan dos tipos de comunidades vegetales: bosques de algarrobo y estepas arbustivas (Dip 2018). 


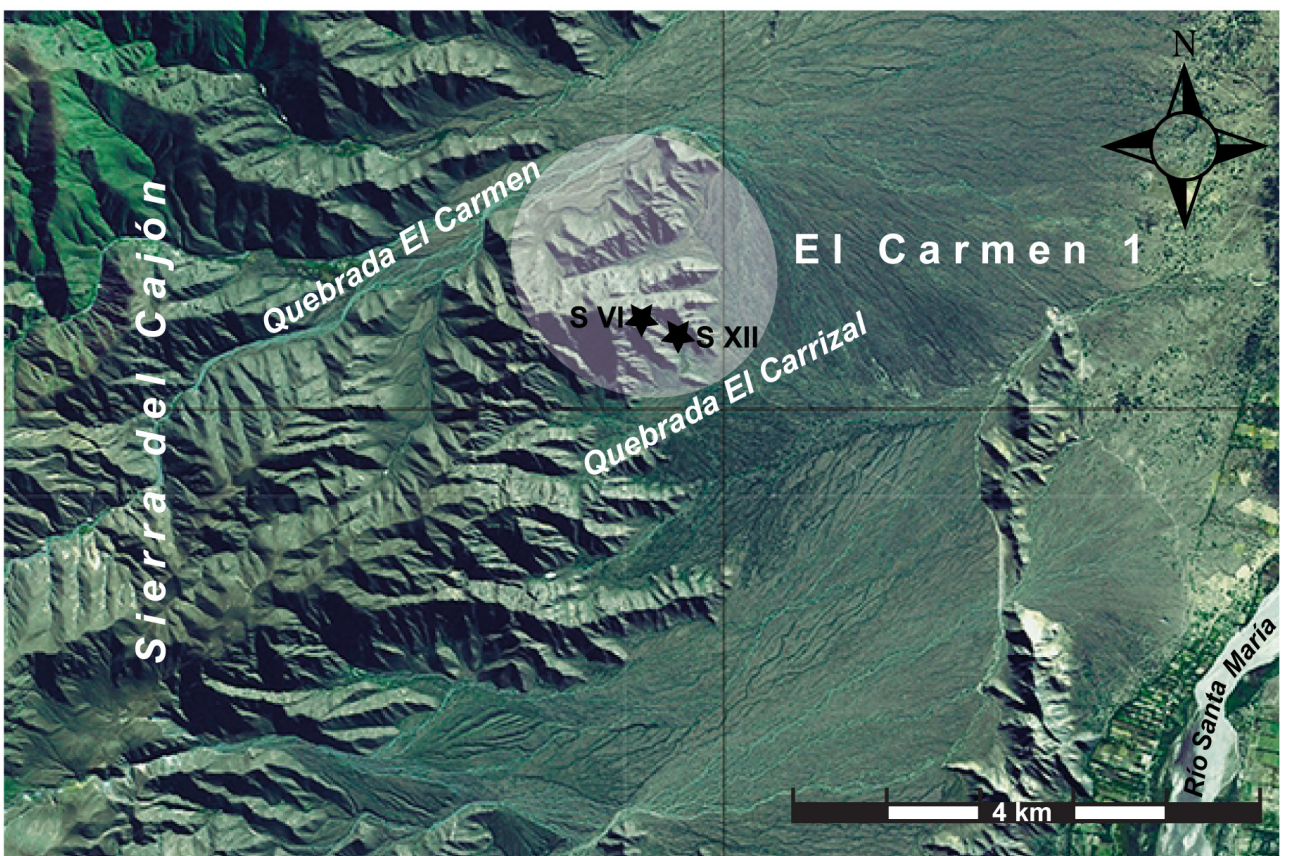

Figura 2. Localización de los Sectores VI y XII del sitio El Carmen 1, Sierra del Cajón, provincia de Tucumán (Fuente: Atlas Tucumán 2014, Instituto Geográfico Nacional 1: 100000).

Location of Sectors VI and XII of the El Carmen 1 site, Sierra del Cajón, Tucumán province (Source: Atlas Tucumán 2014, Instituto Geográfico Nacional 1: 100000).

El sitio se extiende sobre una superficie aproximada de 150 ha (incluyendo espacios sin construcciones formales) y presenta una segmentación de 15 Sectores (I$\mathrm{XV}$ ) funcional y topográficamente distintos: residenciales, productivos, defensivos y comunicacionales (Cantarelli 2019; Coll Moritan et al. 2015).

En base a los datos obtenidos de tres fechados radiocarbónicos, el poblado estuvo ocupado durante la segunda mitad del periodo Intermedio Tardío, entre el 1222 y 1406 DC (Coll Moritan et al. 2015). Estos fechados se corresponden con las evidencias obtenidas de los estudios cerámicos de excavación y superficie, que permitieron establecer que: (1) los fragmentos mayormente representados son los pertenecientes al periodo Intermedio Tardío y (2) en las quebradas El Carmen y El Carrizal circularon cerámicas con iconografía tardía así como diversas técnicas de acabado (peinado, alisado y pulido) de uso extendido durante los contextos tardíos (Cantarelli 2019:32).

Detodoslos sectores ${ }^{2}$,elVIyel XII presentanunamayor cantidad de construcciones. El estudio pormenorizado de las estructuras arquitectónicas y las relaciones espaciales sujetas a su disposición, constituyen una de las claves para entender la racionalidad pretérita de quienes las crearon y utilizaron (Mañana Borrazás et al. 2002). Sobre la base de los datos obtenidos del análisis formal aplicado a las estructuras de los Sectores VI y XII (Cantarelli 2017, 2019; Coll Moritan et al. 2015) se realiza el análisis de percepción (visualización, circulación y gamma). Las características principales de los sectores se sintetizan en la Tabla 1 , donde se pueden constatar diferencias notables en torno al tipo de localización, asentamiento, presencia y/o ausencia de arquitectura productiva, cantidad de estructuras arquitectónicas, composición arquitectónica, cantidad de recintos y de unidades compuestas.

Los Sectores VI y XII fueron habitados durante el periodo Intermedio Tardío. De las excavaciones realizadas en el Sector VI (recinto 13) se obtuvo material carbónico que fue procesado y cuyo resultado permitió establecer su ocupación entre el 1281 y 1404 DC (Coll Moritan et al. 2015). Si bien para el Sector XII no se realizaron excavaciones estratigráficas para afinar la cronología, el estudio de la cultura material cerámica y arquitectónica permitió postular que compartía el repertorio alfarero y constructivo afín a la cultura santamariana (Cantarelli 2019). Sin embargo, queda abierta la posibilidad de que los sectores bajo estudio fueran habitados en momentos distintos.

El Sector VI se localiza en el límite de las quebradas El Carmen y El Carrizal sobre una cima plana de 0,4 ha. Es el segundo sector más edificado del asentamiento, presentando65 estructuras. Secompone principalmente de recintos, algunos muros aislados y antiguos tramos de caminos. Sin embargo, el 90,77\% de las estructuras arquitectónicas corresponde a recintos y espacios abiertos. Estos últimos constituyen estructuras que no se encuentran delimitadas totalmente por muros sino que conservan, al menos, uno de sus lados abiertos. 
Tabla 1. Características de los Sectores VI y XII.

Characteristics of Sectors VI and XII.

\begin{tabular}{lcc}
\hline \multicolumn{1}{c}{ Sector } & VI & XII \\
\hline Localización & Qdas. El Carmen y El Carrizal & Qda. El Carrizal \\
\hline Asentamiento & Cima plana & Ladera \\
\hline $\begin{array}{l}\text { Presencia de arquitectura } \\
\text { productiva }\end{array}$ & no & sí \\
\hline $\begin{array}{l}\text { Composición arquitectónica } \\
\begin{array}{l}\text { Cantidad de estructuras } \\
\text { arquitectónicas }\end{array}\end{array}$ & recintos, muros, caminos & $\begin{array}{c}\text { recintos, terrazas, muros de contención, } \\
\text { líneas de piedra, morteros }\end{array}$ \\
\hline $\begin{array}{l}\text { Cantidad de recintos } \\
\text { Cantidad de unidades }\end{array}$ & 65 & 92 \\
\hline
\end{tabular}

Por último, en el sector no se hallaron evidencias de estructuras asociadas a actividades productivas como: morteros, terrazas, muros y murallas defensivas, entre otras.

El Sector XII se localiza sobre la ladera norte de la Quebrada El Carrizal. Es el sector más edificado del poblado y cuenta con 92 estructuras de las cuales 28 constituyen recintos. A diferencia del VI presenta una mayor variabilidad edilicia. Se compone de recintos, terrazas, muros de contención, líneas de piedra y morteros públicos. A partir del relevamiento arquitectónico se reconocieron estructuras vinculadas a espacios habitacionales y otras asociadas a tareas de defensa y control del asentamiento. Así como también se registró un recinto de grandes dimensiones $\left(144 \mathrm{~m}^{2}\right)$, probablemente destinado al encierro de ganado durante una parte del año.

\section{Del Análisis Formal al Análisis de Percepción}

La metodología implementada sigue los lineamientos desarrollados de la Arqueología del Paisaje (Ayán Vila 2003; Criado-Boado 1999; Mañana Borrazás 2003, 2005; Mañana Borrazás et al. 2002), que combina técnicas provenientes de distintas disciplinas y se sintetiza en dos tipos de análisis: formal y percepción (Mañana Borrazás et al. 2002). Los análisis formales y de percepción son complementarios, los primeros caracterizan y describen densamente una construcción (Criado-Boado 1999:20) y los segundos tratan de dilucidar la relación existente entre las personas y las construcciones (Mañana Borrazás 2003).

El análisis formal arquitectónico del sitio El Carmen 1 fue realizado por los integrantes del Proyecto Arqueológico Sierra del Cajón (PASC) y publicado en trabajos previos (Cantarelli 2019; Coll Moritan 2018; Coll Moritan et al. 2015). Las actividades realizadas incluyeron relevamientos planialtimétricos y arquitectónicos de las estructuras del sitio. De manera que se obtuvieron planos que permitieron conocer la configuración espacial y distribución de sectores y recintos, así como también se caracterizaron los materiales y las técnicas constructivas empleadas en la arquitectura con el objetivo de conocer las modalidades constructivas existentes.
El análisis de percepción tiene como base el análisis formal porque se trabaja sobre las estructuras arquitectónicas y su organización espacial. El análisis de percepción consiste en el estudio de la lógica perceptiva (Mañana Borrazás et al. 2002) y en la búsqueda del significado social que subyace (Ayán Vila 2003) en la racionalidad del grupo que creó y usó las construcciones (Mañana Borrazás 2003, 2005; Mañana Borrazás et al. 2002). Este estudio se realizó en los Sectores VIy XII. Con un abordaje integral a distintas escalas (macro y micro), suscitó la aplicación de variadas técnicas analíticas: (1) análisis de las condiciones de visualización: visibilidad y visibilización y de circulación (escala macro, unidad de análisis: sector) y (2) análisis gamma (escala micro, unidad de análisis: unidad doméstica).

Los estudios aplicados a escala macro (unidad de análisis: sector) tienen como objetivo evaluar las condiciones de visualización: visibilidad y visibilización (Criado-Boado 1999) y caracterizar las posibilidades de circulación considerando la existencia de barreras naturales y artificiales (Wynveldt y Balesta 2009, 2010).

$\mathrm{El}$ estudio de la visibilidad implica detectar todo aquello que es posible de ser percibido desde la unidad arqueológica señalada; para ello se definen panorámicas y cuencas visuales y se identifican los elementos peculiares naturales y artificiales. El estudio de visibilización se ocupa de analizar cómo se percibe la unidad arqueológica desde fuera; esta técnica se limita a definir desde donde se ve la unidad arqueológica con el objetivo de determinar la existencia de puntos prominentes de vistas y establecer la percepción zonal o puntual. La primera indica que la unidad arqueológica se observa concretamente desde lejos mientras que la segunda indica que solo se percibe la zona porque no se ve concretamente (Criado-Boado 1999:33-34).

El análisis gamma desarrollado a escala micro (unidad de análisis: unidad compuesta ${ }^{3}$ ) tiene como objetivo el ordenamiento del espacio, la caracterización de los accesos posibles y la manera de circular; lo que conduce a revelar las posibles relaciones sociales establecidas entre las personas y las estructuras, así como también entre estas últimas y las personas ajenas (Hillier y Hanson 1984; Sánchez 1998). 
Para ello, se analizan los accesos que conectan espacios con el fin de crear un modelo de permeabilidad que muestre las posibles conexiones inter-espaciales (Hillier y Hanson 1984). El modelo representa los límites espaciales y las puertas que dan acceso a otros espacios. La posibilidad de que ciertas puertas permitan acceder a otros espacios es un factor sumamente importante porque señala como se impone el control de paso (Foster 1989).

Mediante el diagrama de permeabilidad se identifican las relaciones sintácticas entre los espacios. Cada espacio se representa con un círculo y se colocan horizontalmente los casos que poseen el mismo valor (Ayán Vila 2003; Foster 1989). De esta forma se mide el nivel de dependencia junto con el control ejercido en cada caso (simetría: la relación entre $A$ y $B$ es la misma que $B$ con $A$; asimetría: la relación de A con B no es la misma que la de B con A) (cf. Vaquer y Nielsen 2011:309), se cuantifica la cantidad y disposición de los accesos (distribuida: un único acceso exterior; no distribuida: más de un acceso exterior) (cf. Mañana Borrazás et al. 2002:37-38).
Los pasos metodológicos para la realización del análisis gamma son: (1) definir las unidades compuestas, (2) determinar los accesos internos y externos en las unidades, (3) elaborar diagramas para medir la comunicación otorgando valores a cada espacio en función de la permeabilidad y en relación a la entrada, y (4) caracterizar y clasificar los resultados obtenidos. Primeramente se divide entre unidades simétricas y asimétricas, y dentro de cada grupo se realiza una nueva separación entre las unidades que registran un único acceso (tipo de organización no distribuida) y las que presentan más de uno (tipo de organización distribuida).

\section{Resultados de los Análisis de Percepción}

\section{Escala macro: Condiciones de visualización y circulación}

Se definió para el Sector VI una visibilidad panorámica radial (Criado-Boado 1999) (Figuras 3 y 4). Esto significa que desde cualquier punto del sector se tiene una vista

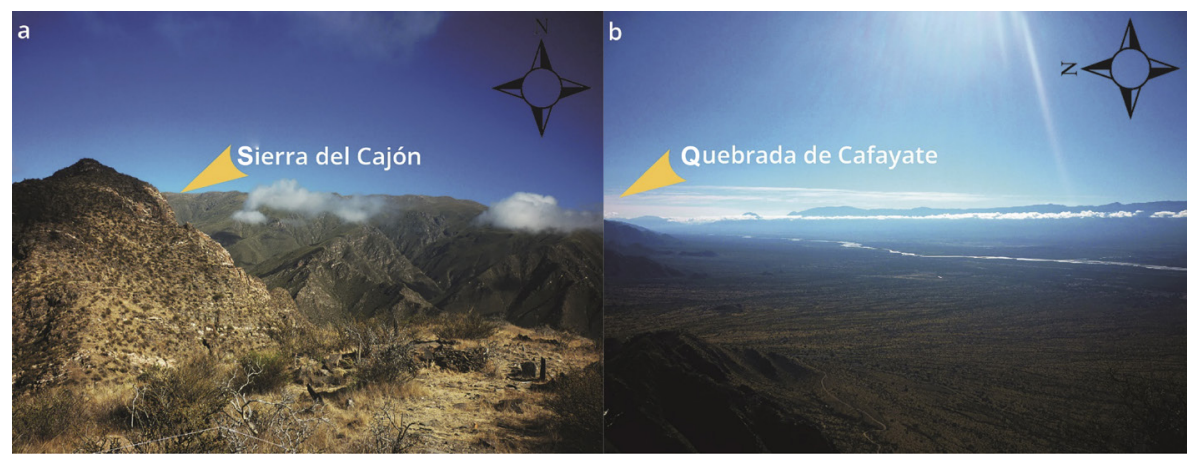

Figura 3. Sector VI: a. Vista hacia la Sierra del Cajón y b. Vista hacia la Quebrada de Cafayate.

Sector VI: a. View to Sierra del Cajón, and b. View to Quebrada de Cafayate.
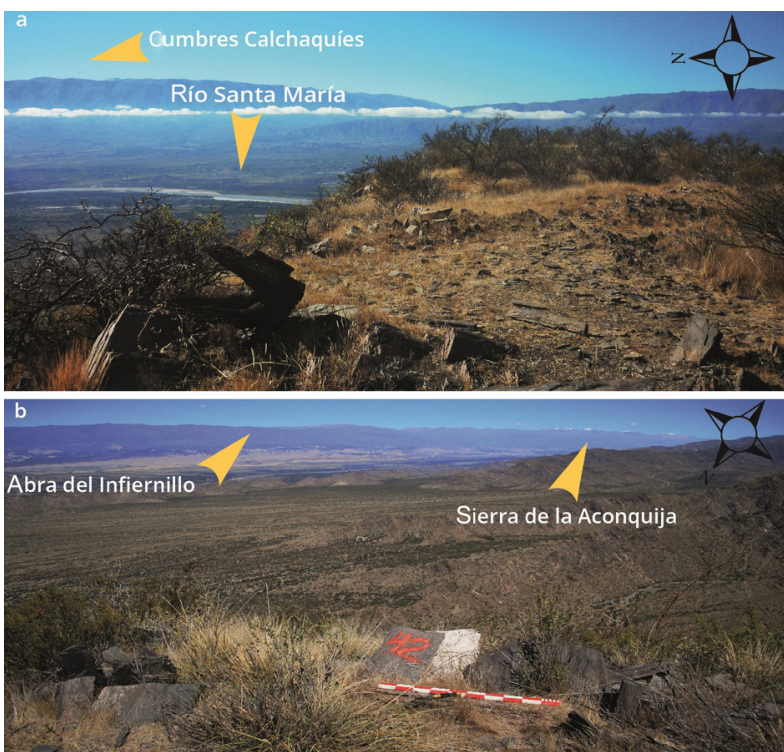

Figura 4. a. Sector VI: Vista hacia Cumbres Calchaquíes y b. Vista hacia el Abra del Infiernillo y la Sierra de Aconquija.

Sector VI: a. View to Cumbres Calchaquies, and b. View to Abra del Infiernillo and Sierra de Aconquija. 
panorámica amplia hacia los cuatro puntos cardinales, desde la cual se observan elementos señeros naturales y culturales. Haciael norte se divisala QuebradadeCafayate, las Cumbres Calchaquíes y el Abra del Infiernillo, en dirección este se aprecia parte del Valle de Santa María, Amaicha del Valle y Fuerte Quemado, hacia el sudeste la Sierra de Aconquija, y por último hacia el oeste se percibe gran parte de la Sierra del Cajón. En cuanto a la visibilización del sector, se pudo determinar la percepción zonal (Criado-Boado 1999), que significa que el sector no se distingue desde fuera, sino que solo se aprecia el entorno sobre el cual se asienta. Desde el camino rural que abre paso entre la Quebrada El Carmen y la localidad de Fuerte Quemado se avista el emplazamiento de los sectores más altos del poblado que se localizan en dos cimas planas y elevadas por encima de los $2.400 \mathrm{msm}$ y se encuentran separados por un collado. En la Figura 5 se puede observar como se percibe la zona donde se emplaza el Sector VI, pero no se puede visibilizar el sector en cuestión.

Para el Sector XII se comprobó un alcance limitado al este (Figura 6). A pesar de su circunscripción visual, desde

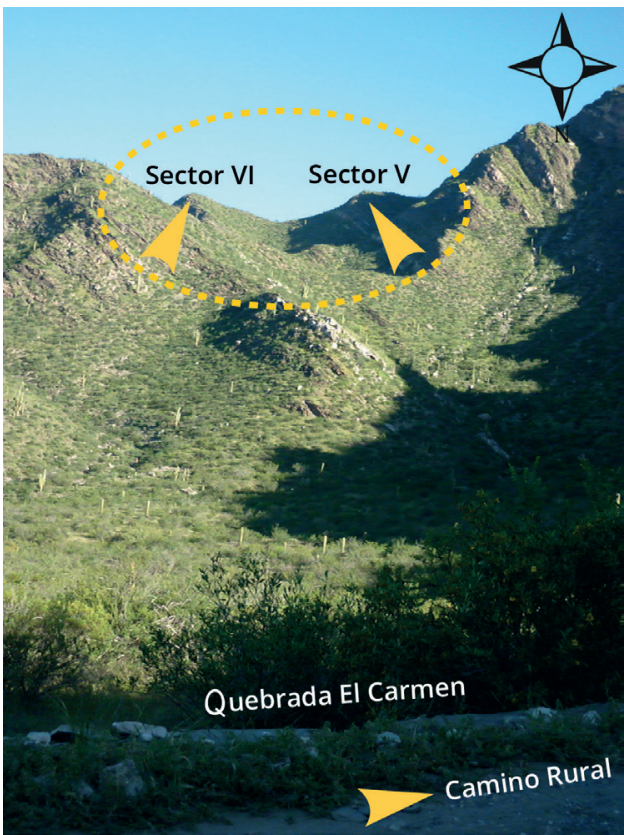

Figura 5. Visibilización del Sector VI desde la Quebrada El Carmen.

View of Sector VI from Quebrada El Carmen.
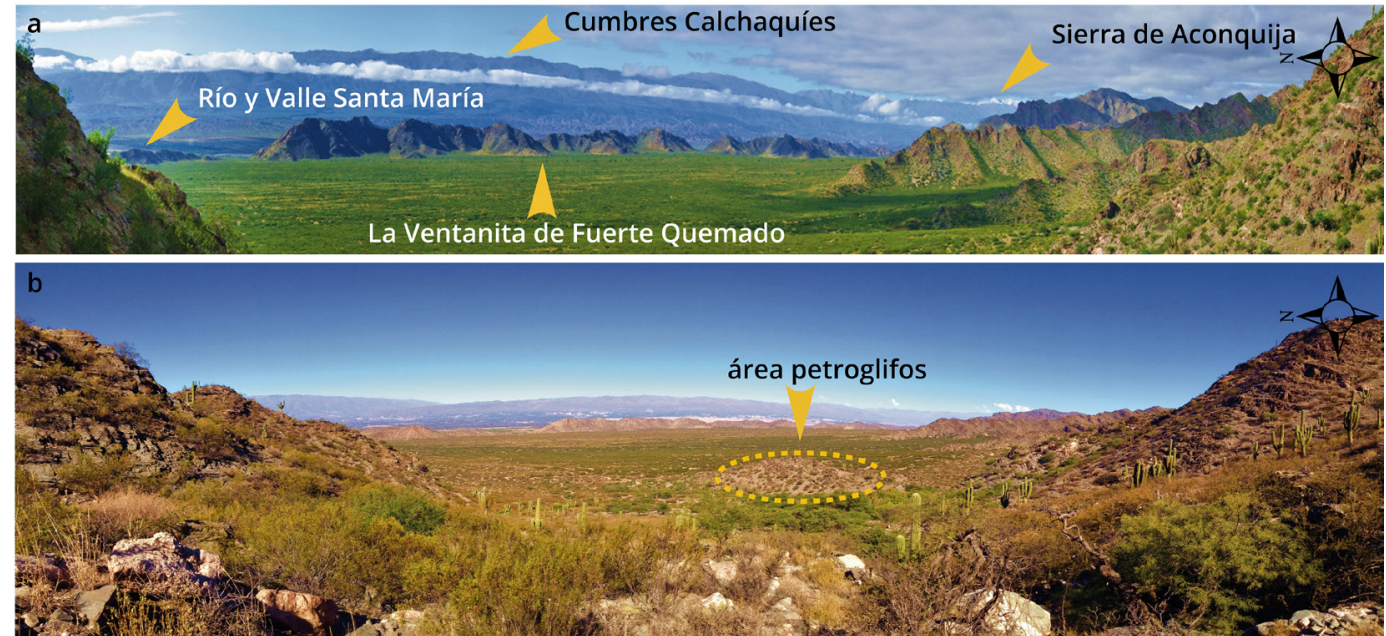

Figura 6. Sector XII: a. Panorámica del Valle de Santa María, Cumbres Calchaquíes, Sierra de Aconquija y el sitio La Ventanita de Fuerte Quemado, b. Panorámica sobre la Quebrada El Carrizal y área de hallazgo de petroglifos (foto: Paula Villegas).

Sector XII: a. Overview of Santa María valley, Cumbres Calchaquíes, Sierra de Aconquija, and the La Ventanita de Fuerte Quemado site, b. Overview of Quebrada El Carrizal and petroglyph discovery area (Photo: Paula Villegas). 
el mismo se observan elementos naturales emblemáticos como las Cumbres Calchaquíes al noreste, la Sierra del Aconquija al sudeste y Fuerte Quemado junto con gran parte del Valle de Santa María al este. Desde la porción central del sector se aprecia nítidamente el entorno donde se hallaron los petroglifos El Carrizal (Cantarelli y Nastri 2019; Quiroga 1931; Vargas et al. 2016).

En la Figura 7 se visualiza el área sobre el cual se asienta el Sector XII desde el sitio arqueológico La Ventanita de Fuerte Quemado. La distancia en línea recta entre los sectores alcanza los $3 \mathrm{~km}$. Asimismo, en la figura se observa la zona de emplazamiento de los sectores de ladera de la Quebrada El Carrizal, sin embargo no se consigue apreciar las construcciones. Los sectores se encuentran sobre dos vaguadas que están separadas por un espolón (Cantarelli 2019). A medida que se aproxima al sector se mejora notablemente la visualización de las estructuras y principalmente se destacan las terrazas defensivas por la elevación de los muros exteriores.

Los dos sectores permanecen encubiertos en el paisaje, sin embargo existe una diferencia. El Sector VI permanece oculto para los forasteros, pero es un "monumento" para los locales (sensu Criado-Boado 1993). De manera que se conjuga un doble vínculo entre: local/forastero y local/local. En este sentido, se considera que un extraño difícilmente podrá deducir a la distancia la existencia de construcciones sobre las cimas más altas, pero las personas que forman parte de la sociedad conocen o imaginan el tipo de asentamiento erigido en el Sector VI.

Una situación diferente es la del Sector XII. Las estructuras más prominentes o aquellas que se destacan en el terreno (p.ej., terrazas defensivas, muros de contención, parapetos) permanecen "exhibidas" (Criado-Boado 1993) para los ajenos al asentamiento y potencialmente para las personas que forman parte de la sociedad.

Continuando con los análisis a escala macro, se estudiaron los posibles accesos a los sectores. $\mathrm{La}$ aproximación al Sector VI se realiza mediante las quebradas El Carmen y El Carrizal (Figura 8). Las alternativas evaluadas en términos de distancia y dificultad arrojaron ventajas y desventajas en cada caso (Cantarelli 2019). La aproximación al Sector VI resulta una tarea difícil, sobre todo si se la compara con el acceso al Sector XII, al cual se ingresa por la quebrada de acceso a El Carrizal. Sin embargo, el hecho de contar con alternativas no lo convierte en un terreno permeable ni vulnerable, sino todo lo contrario. La localización del Sector VI sobre la cima más alta entre las dos quebradas habría garantizado el control visual del área -como fue explicitado en los párrafos anteriores- y de la circulación interna.

Acceder al Sector VI habría implicado un largo recorrido utilizando cualquiera de las dos alternativas. Por la Quebrada El Carmen, el sendero se inicia por el Sector I y presenta una distancia de $1.000 \mathrm{~m}$ en línea recta. En el recorrido se atraviesan y/o bordean ocho sectores (I, II, III, IV, VII, VIII, IX y XI) que presentan 62 estructuras edilicias. Cuatro de los sectores (II, VI, IX y XI) fueron asociados a actividades de defensa y control del asentamiento (Cantarelli 2017, 2019; Coll Moritan et al. 2015). El Sector II cuenta con dos murallas defensivas que cortan transversalmente la quebrada con el fin de inhibir la libre circulación y el Sector IX presenta una estructura circular que se reconoció como posible torreón (Coll Moritan et al. 2015). Mientras que el acceso por la Quebrada El Carrizal se inicia por el Sector XII y la distancia a recorrer se reduce a $500 \mathrm{~m}$ en línea recta.

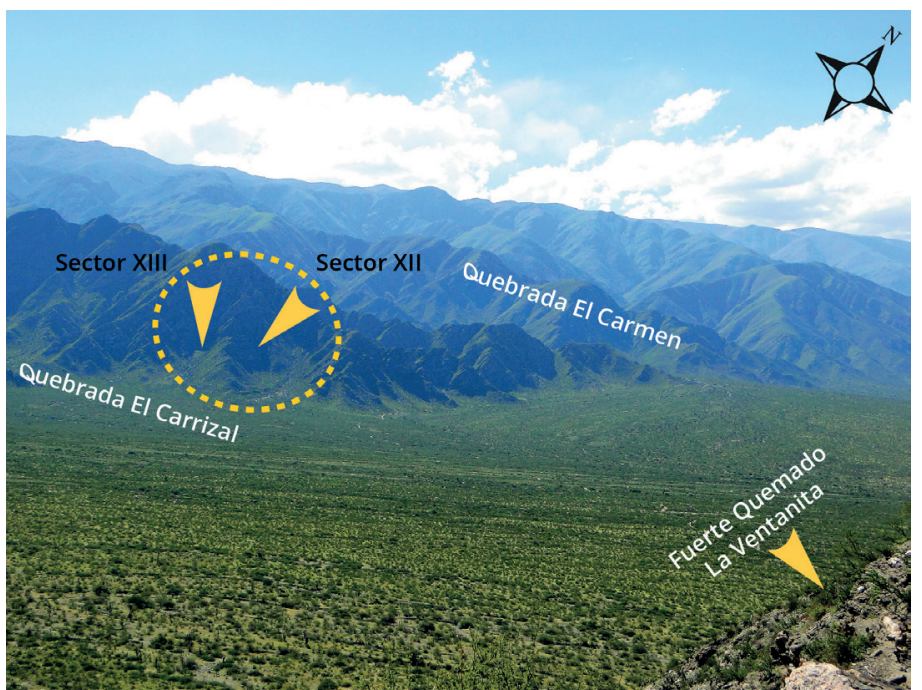

Figura 7. Visibilización del Sector XII desde el sitio La Ventanita de Fuerte Quemado (foto: Paula Villegas). View of Sector XII from the La Ventanita de Fuerte Quemado site (Photo: Paula Villegas). 


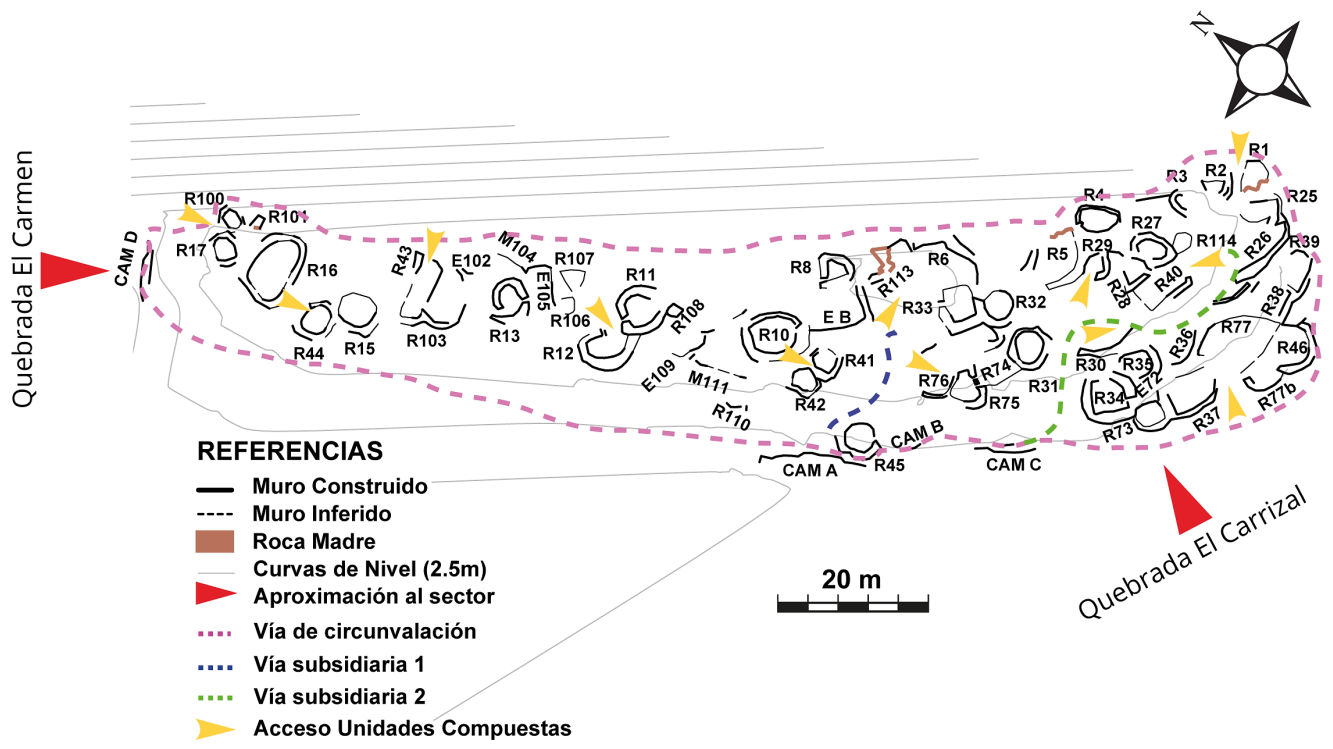

Figura 8. Circulación del Sector VI: vía de circunvalación y vías subsidiarias (Plano: Coll Moritán et al. 2015:107).

Circulation of Sector VI: ring road and subsidiary roads (Plan: Coll Moritan et al. 2015:107).

El Sector XII presenta una gran cantidad de estructuras edilicias (Tabla 1), 24 de las cuales fueron vinculadas con tareas de defensa del asentamiento (terrazas defensivas, muros de contención) (Cantarelli 2017, 2019).

$\mathrm{Al}$ alcanzarse la cima plana sobre la que se asienta el sector no hay evidencias de obstáculos ni de barreras naturales y artificiales (Wynveldt y Balesta 2010:615) que impidan la circulación. Los recintos y espacios se articulan con otros -o no- formando unidades de vivienda compuesta y resulta fácil circular entre claros, aberturas y pasos. El plano del Sector VI (Figura 8) muestra la ausencia de aglomeración de estructuras. La distribución propicia la interacción al interior de las unidades compuestas, pero marca límites concretos entre las mismas.

Se pudo establecer la existencia de un camino principal de circunvalación que rodea al conjunto arquitectónico y del cual parten dos senderos subsidiarios e internos (Figura 8: vía 1 y vía 2) que acceden a las unidades compuestas más encubiertas. Se define para el Sector VI una organización espacial concentrada sobre una pampa de altura de difícil acceso y entendida como una barrera natural en sí misma (Wynveldt y Balesta $2009,2010)$. No se han registrado barreras artificiales como muros y murallas.

Como se mencionó, la aproximación al XII se realiza por el sector homónimo. El Sector XII se emplaza sobre una ladera que presenta un sistema de profundas cárcavas asociadas a prominentes riscos que convierten un escenario aparentemente accesible en un territorio (cf. Manzanal 2007:33) protegido y difícilmente circulable.

Probablemente se hayan desplegado variadas estrategias para condicionar la circulación, implementado el uso de los recursos artificiales. Se registraron mayormente dos tipos de estructuras edilicias: muros de contención y terrazas defensivas (construidas a partir de un muro empotrado y con una línea de lajas o parapetos por encima) (Cantarelli 2017). Sin embargo, no se reconocieron tramos de antiguos caminos ni posibles vías de circulación apropiadas. Se considera como posibilidad que las personas utilizaran las cárcavas como senderos.

\section{Vegetación y relieve}

Se considera que las profundas cárcavas integradas con pendientes acentuadas y riscos prominentes, así como la espesa vegetación espinosa, entorpecen actualmente la circulación y dificultan el acceso a los recintos y unidades compuestas del Sector XII. De manera que se considera que en el pasado habrían actuado como barreras naturales (Wynveldt y Balesta 2009, 2010) en el funcionamiento del sector.

A partir de mediciones manuales en el campo, se determinó que el sistema de cárcavas naturales del Sector XII provoca una visibilidad diferencial inter-espolón (CriadoBoado 1999) que inhibe la circulación intra-sector (Figura 9).

Asímismo, se registró que las construcciones del Sector XII se realizaron entre los 1.998 y 2.088 msm 


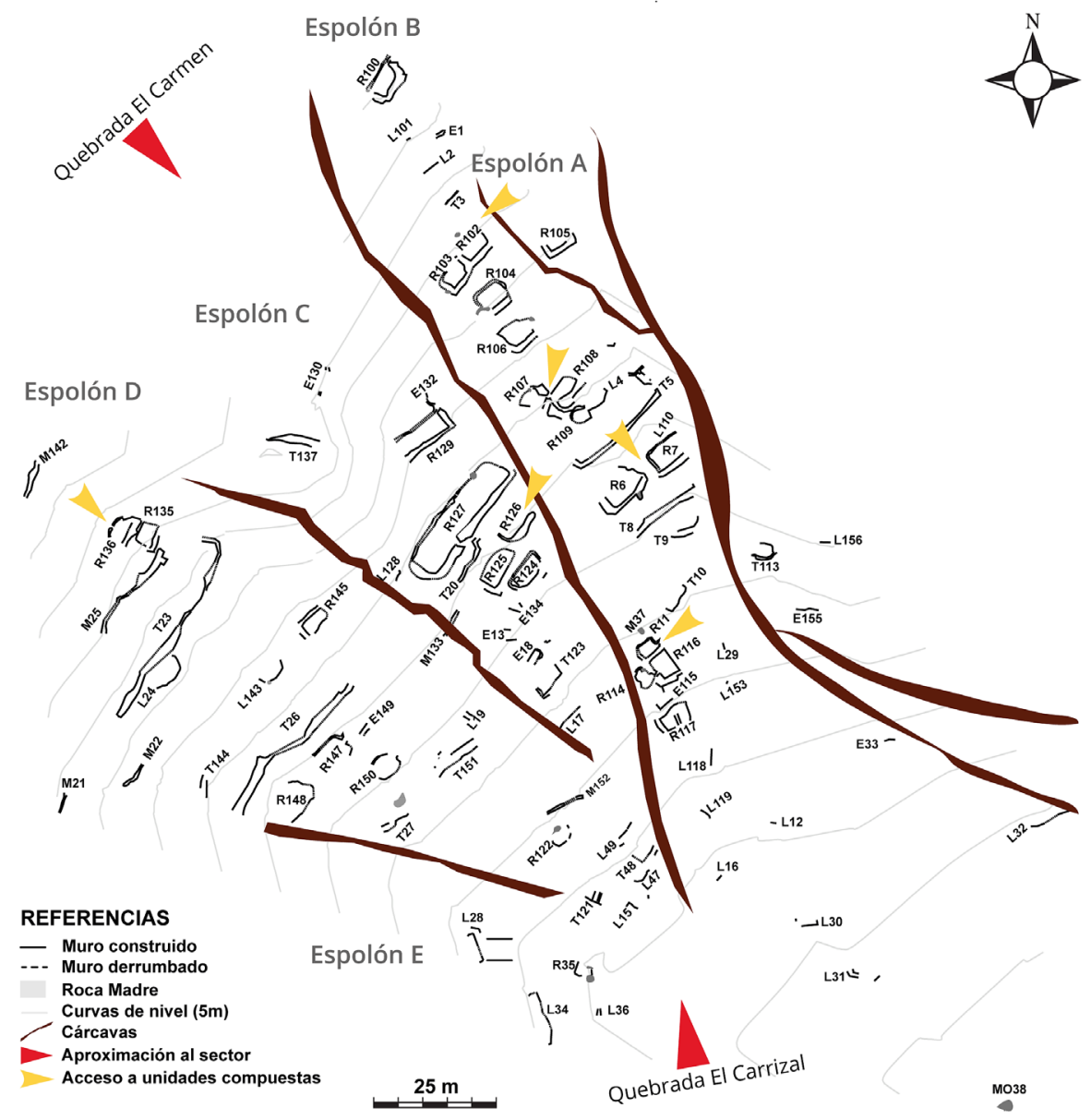

Figura 9. Circulación del Sector XII: sistema de cárcavas naturales (A-E).

Circulation of Sector XII: system of natural gullies (A-E).

donde se desarrolla la estepa arbustiva de xerófilas que constituye el tipo de formación vegetal más característico del Monte (Cabrera 1971). Las especies conocidas en esta cubierta son: montenegro (Bulnesia schickendantzii), jarillas (Larrea divaricata y L. cuneifolia), brea (Cercidium praecox), retama (Senna aphylla), churqui (Prosopis torquata) y garabato o radajilla (Plectocarpa rougesii), y entre las cactáceas se destacan la penca (Opuntia sulphurea), el ucle (Cereus aethiopis) y el cardón (Echinopsis tersheckii) (cf. Dip 2018:28). Por encima de los $2.100 \mathrm{msm}$ cambia levemente la vegetación y aparecen las especies prepuneñas y la formación se considera como un ecotono, es decir, una zona de transición entre el monte y la prepuna (Dip 2018).

La bibliografía sobre la fitogeografía del lugar muestra que el predominio de la estepa arbustiva se presenta en los sectores más bajos del asentamiento (p.ej., XII), mientras que los sectores emplazados por encima de los $2.400 \mathrm{msm}$ (p.ej., VI) presentan una formación vegetal semejante a la prepuna (Dip 2018). Esta caracterización permitió explicar la diferencia de la cubierta vegetacional entre los sectores, así como también, proponer el funcionamiento como barrera natural en el XII.

\section{Escala micro: Análisis Gamma}

Los Sectores VI y XII están compuestos por diferentes tipos de estructuras, pero una parte considerable de ellas corresponde a recintos habitacionales. Los recintos pueden encontrarse aislados o formando unidades compuestas. Estas últimas conforman la unidad de análisis en los estudios de movimiento. Se implementó el análisis gamma en 10 unidades del Sector VI y en seis del Sector XII.

Como se mencionó previamente, el Sector VI se emplaza sobre una cima plana. La elevación de los recintos varía entre los 2.441 (recinto 41 , unidad 
compuesta 16) y $2.453 \mathrm{msm}$ (recinto 108 , unidad compuesta 15). La elevación de los recintos no se consideró como un factor determinante para el análisis de movimientos en las unidades domésticas por el relieve del sector, hecho por el cual en la Tabla 2

permanece ausente la fila de cota msm.

Tabla 2. Sector VI: características de las unidades compuestas.

Sector VI: characteristics of the composite unit.

\begin{tabular}{|c|c|c|c|c|}
\hline Unidad Compuesta & Recinto & Área $\left(\mathrm{m}^{2}\right)$ & Forma/Planta & Comunicación \\
\hline \multirow{2}{*}{12} & R 17 & 6,37 & cuadrangular & exterior \\
\hline & R 100 & 3,88 & circular & exterior \\
\hline \multirow{2}{*}{13} & R 15 & 16,42 & circular & exterior \\
\hline & R 44 & 10,88 & circular & exterior \\
\hline \multirow{2}{*}{14} & R 43 & 22,34 & rectangular & recinto 103 \\
\hline & R 103 & 24,65 & rectangular & recinto 43 \\
\hline \multirow{3}{*}{15} & R 11 & 13,9 & circular & recinto 12 y 108 \\
\hline & R 12 & 13,89 & rectangular & exterior \\
\hline & R 108 & 2 & irregular & recinto 11 \\
\hline \multirow{2}{*}{16} & R 41 & 6,33 & circular & exterior \\
\hline & R 42 & 7,42 & circular & exterior \\
\hline \multirow{4}{*}{17} & R 31 & 12,16 & circular & recinto 74 \\
\hline & R 75 & 10,58 & irregular & recinto 74 \\
\hline & R 74 & 23,7 & irregular & recinto 31,75 y 76 \\
\hline & R 76 & 49 & irregular & recinto 74 \\
\hline \multirow{6}{*}{18} & R 6 & 83 & irregular & exterior \\
\hline & R 10 & 23,78 & rectangular & espacio B \\
\hline & R 32 & 11,28 & circular & recinto 33 \\
\hline & R 33 & 15,25 & cuadrangular & exterior \\
\hline & R 112 & & no observable & exterior \\
\hline & R 113 & 8,63 & cuadrangular & exterior \\
\hline \multirow{6}{*}{19} & R 5 & 28,14 & irregular & exterior \\
\hline & R 27 & 7,6 & circular & recinto 28 y 114 \\
\hline & R 28 & & irregular & recinto 27 y 40 \\
\hline & R 29 & 5,19 & irregular & exterior \\
\hline & $\mathrm{R} 40$ & 24 & rectangular & recinto 28 \\
\hline & R 114 & 4,7 & circular & recinto 27 \\
\hline \multirow{2}{*}{20} & R 1 & 10,02 & irregular & exterior \\
\hline & R 2 & & no observable & exterior \\
\hline \multirow{11}{*}{21} & R 36 & & no observable & recinto 30 y 38 \\
\hline & R 38 & 22,23 & rectangular & recinto 36 y 39 \\
\hline & R 39 & 14,46 & rectangular & recinto 38 \\
\hline & R 46 & 23,77 & cuadrangular & recinto $77 b$ \\
\hline & R 77 & 50,98 & irregular & exterior \\
\hline & R $77 \mathrm{~b}$ & 11,36 & semicircular & recinto 46 \\
\hline & R 34 & 17,15 & cuadrangular & espacio 72 \\
\hline & R 35 & 13 & cuadrangular & espacio 72 \\
\hline & R 37 & 25,29 & rectangular & espacio 72 \\
\hline & R 73 & 9,24 & cuadrangular & espacio 72 \\
\hline & R 30 & & no observable & recinto 36 \\
\hline
\end{tabular}


En el sector se registraron mayormente unidades compuestas por dos recintos habitacionales (Tabla 2). En menor medida, se hallaron unidades conformadas hasta por seis recintos y un único caso por 12 recintos. En cuanto a la forma de las plantas de los recintos, no se determinó una tendencia uniforme, sino que predomina la diversidad. Mayormente se destacan las estructuras circulares e irregulares, seguidas por las rectangulares y cuadrangulares, registrándose un único caso semicircular. El tamaño ${ }^{4}$ de los recintos varía entre 2 y $83 \mathrm{~m}^{2}$. Principalmente se registraron recintos con un tamaño de 10,01 a $40 \mathrm{~m}^{2}$. Tales dimensiones propician la hipótesis de que hayan estado techados totalmente, o al menos de forma parcial (Coll Moritan et al. 2015:106) y fueran utilizados como unidades habitacionales (Nielsen 2001). En segundo lugar, aparecen los recintos que presentan superficies menores a $10 \mathrm{~m}^{2}$. Estos últimos constituirían recintos de molienda o almacenaje (Raffino 1988).

De la excavación del recinto 11 de la unidad compuesta 15 (recintos 11, 12 y 108) se recuperaron únicamente fragmentos cerámicos (Coll Moritan et al. 2015). La muestra total fue de 193 fragmentos pulidos y alisados, con pastas finas y compactas. Esta cerámica se caracterizó como vajilla de servicio (Scattolin et al.
2015). Se consideró como posibilidad que el recinto 11 funcionara como un patio y el recinto 12 como zona de descanso, mientras que el 108 que posee una superficie de $2 \mathrm{~m}^{2}$ fuera utilizado como depósito de alimentos (Cantarelli 2017).

Como se mencionó, se determinaron 10 unidades compuestas en el Sector VI. Los resultados obtenidos del análisis gamma permitieron clasificar tres grandes tipos: (1) unidades compuestas con relaciones simétricas y organización no distribuida, (2) unidades compuestas con relaciones asimétricas y organización no distribuida, (3) unidades compuestas con relaciones asimétricas y organización distribuida.

Dentro del primer grupo (unidades compuestas con relaciones simétricas y organización no distribuida) se encuentran las unidades 12, 13, 16 y 20 (Figura 10). Todas presentan la misma estructura, están compuestas por dos recintos asociados que son independientes entre sí (simetría) pero dependientes de un mismo espacio exterior (organización no distribuida).

Dentro del segundo grupo (unidades compuestas con relaciones asimétricas y tipo de organización no distribuida) aparecen las unidades 14, 15, 17 y 18 (Figura 10). Aquí se observa variabilidad en lo que respecta a la cantidad de estructuras que componen las unidades. Estas

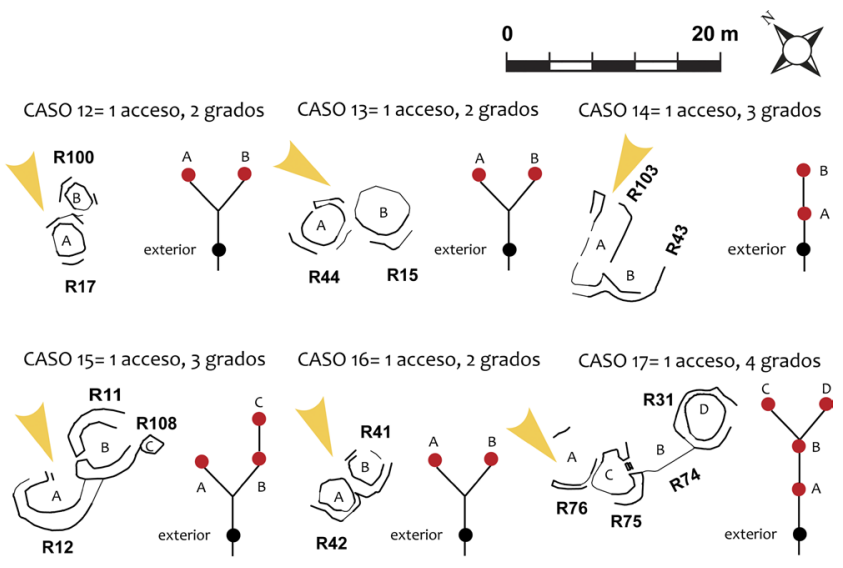

CASO $18=1$ acceso, 3 grados
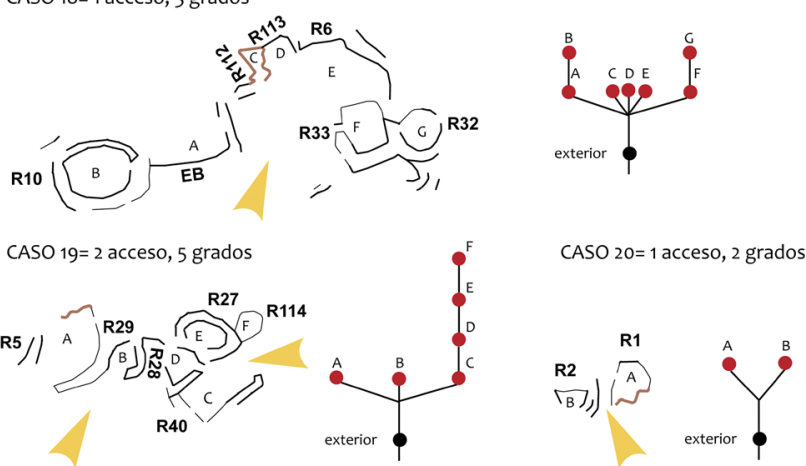

Figura 10. Análisis gamma de las unidades compuestas del Sector VI.

Gamma analysis of composite units of Sector VI. 
varían de dos hasta siete recintos inclusive. También varía la forma en la cual se conectan los recintos internamente, observándose casos en que se establecen relaciones tanto asimétricas como simétricas al interior de las unidades. En la Figura 10 se puede observar como en los casos 15, 17 y 18 aparecen recintos con valores similares, hecho por el cual se colocaron en el diagrama en la misma horizontalidad. En el caso 15: espacios A y B, en el caso 17: espacios C y D y en el caso 18: espacios A, C, D, E y F y espacios B y G. A pesar de las varianzas mencionadas, todas las unidades compuestas cumplen con el mismo tipo de organización no distribuida, lo que significa que poseen un único ingreso exterior.

Dentro del tercer grupo clasificado (unidades compuestas asimétricas y tipo de organización distribuida) se encuentran las unidades 19 y 21 (Figura 10 y 11). Estas se diferencian del grupo 2 porque poseen doble entrada que denota una organización distribuida. La unidad 19 posee seis estructuras mientras que la 21 presenta una docena. La unidad 19 tiene dos accesos diferentes, uno localizado al sudoeste y otro al este. Si bien prevalece la relación asimétrica entre los recintos, como en el caso anterior, se pudieron determinar espacios que presentan el mismo valor: A, B y C. A través de los mismos se accede fácilmente a la unidad. El espacio C como se observa en la Figura 10 posee control directo sobre los espacios restantes. Por último, la unidad 21 (Figura 11) presenta una mayor complejidad respecto a las anteriores, ya que está formada por una docena de recintos. En la misma se registraron dos accesos, uno por el lado sur y otro por el norte. Desde estos se ingresa directamente a los espacios A, B y C por el lado sur e I por el norte. Esto quiere decir que todos estos espacios presentan el mismo valor, habiéndose colocado en el diagrama horizontalmente. Luego, de los espacios
A, C e I es posible acceder al resto de las estructuras. De esta manera se observan las relaciones asimétricas establecidas. La diferencia central con la unidad 19 radica en la cantidad de recintos, además se pudo determinar que la accesibilidad al espacio $\mathrm{H}$ (en la unidad 21) era factible por los dos accesos (norte y sur).

La descripción pormenorizada de las unidades compuestas permitió comprender la estructura, complejidad y conectividad interna en cada caso. Los resultados del análisis gamma muestran mayormente que los recintos se conectan entre sí formando principalmente sistemas asimétricos, observándose también que cuatro unidades se conectan mediante relaciones simétricas. En la mayoría de los casos se registró un único acceso a la unidad, que se traduce en una organización no distribuida. Sin embargo, se pudo registrar que dos de las unidades presentaban dos accesos. En relación a la localización de los accesos exteriores, no se registró una tendencia específica, sino que los ingresos a las unidades se construyeron en distintas orientaciones.

El Sector XII se asienta sobre una de las laderas de la Quebrada El Carrizal. Como se puede observar en la Tabla 3, la elevación de los recintos varía entre los 2.001 (recinto 116, unidad compuesta 4) y $2.043 \mathrm{msm}$ (recinto 136, unidad compuesta 3).

Las unidades están compuestas principalmente por dos, tres y cinco estructuras (Tabla 3). Se determinaron mayormente formas irregulares, mientras que son pocos los casos de plantas rectangulares. El tamaño de las estructuras varía mayormente entre los 8 y $38 \mathrm{~m}^{2}$, es decir que casi todas las estructuras oscilan entre los 10,01 y $40 \mathrm{~m}^{2}$. Este tamaño constituye un indicador de que hayan estado techados total o parcialmente. Solo dos recintos presentan una planta inferior a $10 \mathrm{~m}^{2}$.
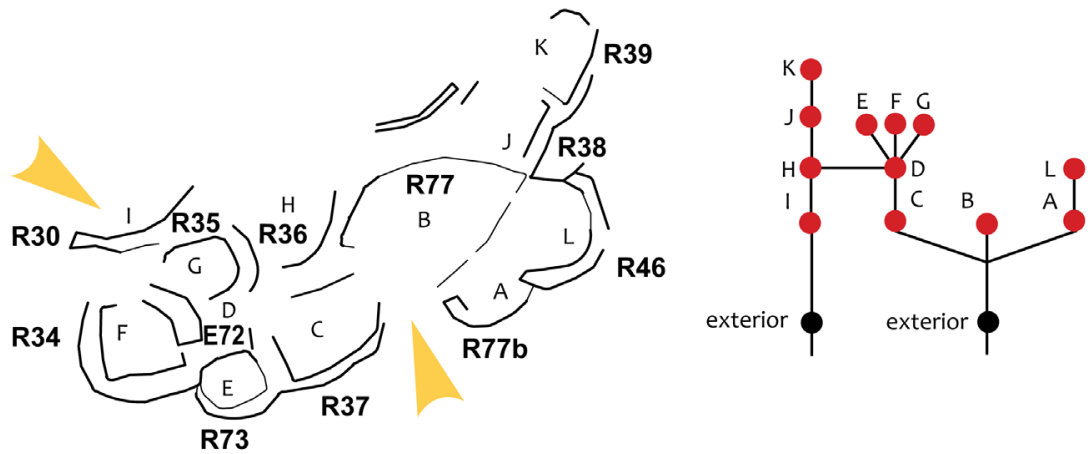

Figura 11. Análisis gamma de las unidades compuestas del Sector VI.

Gamma analysis of composite unite of Sector VI.

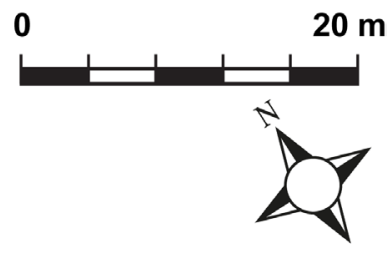


Tabla 3. Sector XII: características de las unidades compuestas.

Sector XII: characteristics of the composite unit.

\begin{tabular}{|c|c|c|c|c|c|}
\hline $\begin{array}{c}\text { Unidad } \\
\text { Compuesta }\end{array}$ & Estructura & Área $\left(m^{2}\right)$ & Forma/Planta & Comunicación & Cota $(\mathrm{msm})$ \\
\hline \multirow{2}{*}{1} & R 6 & 32,55 & irregular & aterrazado exterior & 2.013 \\
\hline & R 7 & 38,33 & irregular & aterrazado exterior & 2.014 \\
\hline \multirow{2}{*}{2} & R 102 & 14,32 & irregular & recinto 103 & 2.034 \\
\hline & R 103 & 15,49 & irregular & recinto 102 & 2.035 \\
\hline \multirow{2}{*}{3} & R 135 & 14,93 & irregular & recinto 136 & 2.041 \\
\hline & R 136 & 14,71 & irregular & recinto 135 & 2.043 \\
\hline \multirow{3}{*}{4} & R 11 & 9,6 & rectangular & recinto 116 & 2.005 \\
\hline & R 114 & 10,4 & irregular & recinto 116 & 2.002 \\
\hline & R 116 & 19,69 & rectangular & recinto 11 y 114 & 2.001 \\
\hline \multirow{5}{*}{5} & R 107 & 14,87 & irregular & recinto 108 & 2.021 \\
\hline & R 108 & 14,49 & irregular & recinto 107 y rampa-pasillo & 2.021 \\
\hline & R 109 & 8,86 & irregular & espacio 4 & 2.019 \\
\hline & E 4 & & no observable & recinto 109 y rampa-pasillo & 2.019 \\
\hline & Rampa-Pasillo & & & recinto 108 y espacio 4 & \\
\hline \multirow{3}{*}{6} & R 124 & 22,96 & rectangular & recinto 125 & 2.012 \\
\hline & R 125 & 30,95 & irregular & recinto 124 & 2.014 \\
\hline & R 126 & 23,69 & no observable & exterior & 2.015 \\
\hline
\end{tabular}

En el Sector XII se determinaron seis unidades compuestas y los resultados del análisis gamma permitieron clasificar dos tipos: (1) unidades compuestas con relaciones asimétricas y organización no distribuida y (2) unidades compuestas con relaciones simétricas y organización no distribuida.

La mayoría de las unidades se clasificaron dentro del primer tipo (unidades compuestas con relaciones asimétricas y organización no distribuida): 2, 3, 4, 5 y 6 (Figura 12). Se observa una variabilidad en cuanto a la cantidad de recintos (entre dos y cuatro). Sin embargo, en todos los casos se pudieron establecer relaciones asimétricas, así como también se detectó una única modalidad de acceso. Las relaciones asimétricas se ven reforzadas por el relieve del terreno. Los casos 2 y 3 presentan una estructura similar basada en la conectividad de dos recintos mediante un acceso interno. La conexión entre los espacios es unidireccional y se ve reforzada por la diferencia de altitud entre los recintos, que varía entre 1 y 2 m (Figura 12: Cota msm). Los casos 4 y 6 también son semejantes: presentan tres niveles, es decir, recintos a diferentes alturas que se conectan unidireccionalmente y de modo asimétrico. En los dos casos, el espacio C se encuentra doblemente controlado y bajo dependencia de los espacios A y B. El caso 5 aporta mayor variabilidad al grupo. Está conformado por distintos tipos de estructuras (recintos, espacio y pasillo-rampa) y exhibe una mayor complejidad en la conectividad mediante desniveles. En la Figura 12 se puede observar que el espacio A tiene dominio absoluto sobre el espacio B, ambos se encuentran a la misma altitud (Tabla 3). Asimismo, desde el espacio A se accede mediante el pasillo-rampa (espacio C) ascendente al espacio D que termina por dar acceso al E. Este último está triplemente controlado por A, C y D que actúan como filtro y lo convierten en el recinto menos permeable de la unidad -y del sector-. Finalmente, en el diagrama se colocaron en la misma horizontalidad B y $\mathrm{C}$ porque la relación entre ambos es simétrica respecto al espacio A.

El segundo grupo (unidades compuestas con relaciones simétricas y organización no distribuida) está representado por la unidad 1 (Figura 12) y constituye el único caso de relación simétrica entre recintos.

La descripción de las unidades compuestas permitió comprender la estructura, complejidad y conectividad interna en cada caso. Asimismo, la consideración de las características del relieve aportó valiosa información para la determinación de las conexiones entre estructuras distribuidas sobre un desnivel de más de $40 \mathrm{~m}$. Los resultados del análisis gamma muestran mayormente que los recintos se conectan entre sí formando principalmente sistemas asimétricos. En todos los casos se registró un único acceso a la unidad, que se traduce en una organización no distribuida. Finalmente, se pudo determinar que los accesos exteriores a las unidades se localizaron mayormente sobre los muros norte, noroeste y noreste, mientras que no se hallaron accesos sobre los muros sudeste y esto resulta una decisión estratégica para ocultar los ingresos a las unidades. La ubicación de los accesos en los muros próximos a la pendiente 


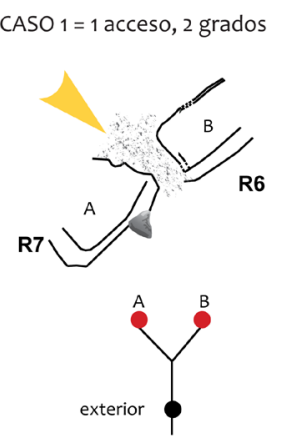

CASO 4 = 1 acceso, 4 grados
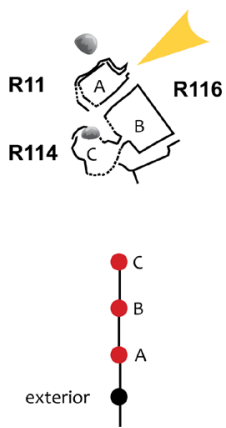

CASO $2=1$ acceso, 3 grados
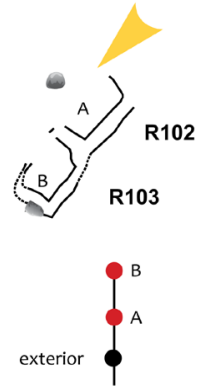

CASO $5=1$ acceso, 5 grados
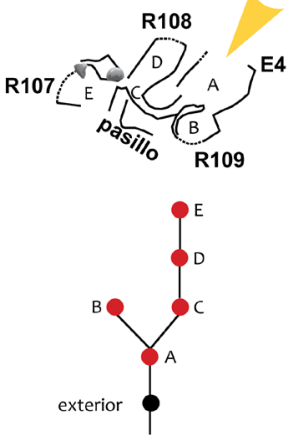
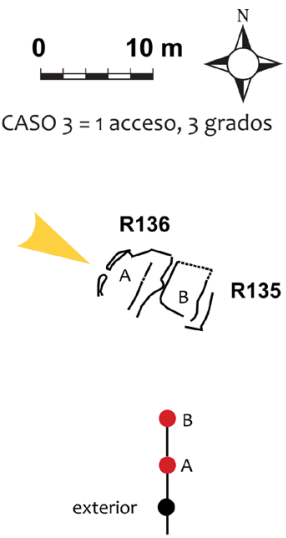

CASO $6=1$ acceso, 4 grados
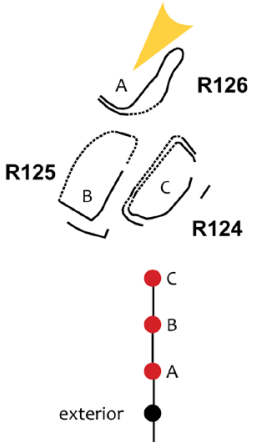

Figura 12. Análisis gamma de las unidades compuestas del Sector XII.

Gamma analysis of composite unite of Sector XII.

produce un efecto de privacidad porque: (1) el factor de obstrusividad juega un rol fundamental haciendo casi invisible e indescifrable el ingreso a la unidad y (2) la circulación queda limitada por su localización produciendo movimientos unidireccionales (p.ej., desde el recinto más elevado hacia el más bajo).

\section{Conclusiones}

Se presentaron y estudiaron los Sectores VI y XII del poblado El Carmen 1. Los mismos son un ejemplo de la diferencia de elevación de sectores y emplazamiento en altura de los sitios tardíos del Valle de Santa María.

Sobre la base de datos formales (localización, asentamiento, presencia y/o ausencia de arquitectura productiva, cantidad de estructuras arquitectónicas, composición arquitectónica, cantidad de recintos y cantidad de unidades compuestas) obtenidos de trabajos anteriores, y con vistas a desarrollar el objetivo planteado, se realizaron análisis de percepción en los Sectores VI y XII del sitio El Carmen 1. Estos análisis incluyeron dos escalas: macro (unidad de análisis: sector) y micro (unidad de análisis: unidad compuesta). A escala macro se estudiaron las condiciones de visualización (visibilidad y visibilización) y circulación, y a escala micro se realizó el análisis gamma. De manera que se evaluaron tres aspectos principales: (1) asentamiento y visibilidad, (2) accesibilidad y circulación y (3) movimiento; que dieron lugar a conocer la dinámica interna de los Sectores VI y XII del poblado.

Para el SectorVIse pudo determinar un asentamiento estratégico en términos visuales. Desde el sector se concibe una panorámica radial con visibilidad nítida hacia cualquiera de los puntos cardinales. Al mismo tiempo, las construcciones edificadas son invisibles desde cualquier punto del paisaje dado que solo se percibe la zona sobre la cual se asienta. De modo que el sector resulta difícilmente visible, pero se encuentra lo suficientemente elevado para que sus habitantes tuvieran control visual del Valle de Santa María y parte de las quebradas interiores y transversales. En los asentamientos emplazados en la banda occidental del Valle de Santa María -dentro del patrón de asentamiento tardío (Tarragó 1987, 1995:231)-, las zonas más elevadas fueron ocupadas por un segmento de la sociedad.

En cambio para el Sector XII se determinó un tipo de asentamiento menos estratégico. Desde el sector sólo se accede a una panorámica parcial y su arco visual está 
limitado al este. Al igual que en el caso del Sector VI, las estructuras a una distancia de $3 \mathrm{~km}$-desde el sitio arqueológico La Ventanita de Fuerte Quemado- no son visibles, sino que se percibe la zona sobre la cual se asienta. La aproximación al sector puede conducir a la visibilización de las estructuras más destacadas.

En el Sector VI se pudo entrever un doble vínculo entre local/no local y local/local. En la relación con los no locales pudo permanecer como oculto, pero en el vínculo con los locales se habría constituido como un espacio monumental para visibilizar su dominio. En este sentido, los habitantes de las cimas más elevadas poseían una capacidad visual mayor que pudo traducirse en términos de conocimiento y constituirse como recurso capital (sensu Bourdieu 1988).

Este primer aspecto permitió plantear que en el poblado El Carmen 1, la espacialidad se habría fundado diferencialmente: el Sector VI habría sido habitado por un segmento social que se mantenía al resguardo de los peligros reales o latentes de la época, al mismo tiempo que poseía el control visual directo sobre las quebradas El Carmen y El Carrizal y gran parte del Valle de Santa María. Así como también poseía alcance visual de la Sierra de Aconquija, las Cumbres Calchaquíes, el Abra del Infiernillo y hasta la Quebrada de Cafayate. En cambio, el grupo social del Sector XII se habría limitado a ocupar y vivir las zonas más bajas (laderas, cono aluvial, etc.), es decir la periferia expuesta a las dificultades y adversidades de la coyuntura socio-política, convirtiéndose asimismo en la línea de seguridad de los grupos que habitaron terreno arriba.

Estas características corresponden a un patrón de asentamiento jerarquizado. Para el cual se estableció que la ocupación del espacio estaba sujeta al modelo de organización social jerarquizada y la distancia social respecto al curaca se materializaba en la distancia física (Tarragó 1987). De manera que la ocupación del espacio, pudo entenderse como el reflejo de la estructura social.

En cuanto a la accesibilidad a los sectores, se pudo determinar las diferencias mediante la caracterización de los senderos de ingreso y la evaluación de la circulación al interior de los mismos. La descripción de los senderos muestra la difícil accesibilidad al Sector VI y expone la diferencia con el XII, el cual asume el rol de entrada de acceso al asentamiento por la Quebrada El Carrizal.

Los resultados mostraron que los habitantes del Sector VI des-localizaron el sistema de seguridad hacia los sectores situados sobre altitudes inferiores. Es debido a esto que la cima carece y prescinde de barreras artificiales que impidan el acceso y/o refuerzos internos (p.ej., muros de contención y terrazas defensivas, parapetos, murallas defensivas, entre otros). En cuanto a la circulación intra-sector se ve manifestada la distancia y separación entre las unidades domésticas como modo de sociabilización, hallándose construcciones arquitectónicas con características físicas compatibles con depósitos de alimentos, lo que permitiría indicar la planificación individual a escala unidad habitacional.

Mientras que en el Sector XII se pudo determinar la existencia de un sistema de barreras artificiales y naturales, que combinadas habrían otorgado seguridad a sus habitantes y al resto del poblado. No se identificaron posibles vías de circulación, pero es probable que hayan utilizado las cárcavas a modo de senderos.

El estudio de movimiento realizado en las unidades compuestas de los sectores arrojó novedosa información. Se pudo determinar que en el Sector XII la mayoría de las unidades se estructuraron mediante relaciones asimétricas, generando así espacios controlados y difícilmente accesibles para personas ajenas. Así como también se detectó una única modalidad de ingreso localizada en los muros norte, noroeste y noreste. No se hallaron accesos exteriores sobre los muros de orientación sur, lo que se traduce en una estrategia para el ocultamiento de los ingresos. La ubicación de los accesos en los muros próximos a la pendiente produce un efecto de privacidad porque: (1) el factor de obstrusividad juega un rol fundamental haciendo casi invisible e indescifrable el ingreso a la unidad y (2) la circulación queda limitada por su localización produciendo movimientos unidireccionales (p.ej., desde el recinto más elevado hacia el más bajo).

En relación al segundo de los motivos, se consideró que el relieve resultó la explicación más racional en torno a la conectividad de algunos de los espacios. De manera que se pudo utilizar la inclinación de la montaña para la construcción de unidades compuestas escalonadas.

En el Sector VI se registraron unidades compuestas estructuradas tanto en base a sistemas asimétricos (seis casos) como simétricos (cuatro casos). En la mayoría de las unidades se pudo determinar un tipo de organización no distribuida que implicó el uso de un único acceso externo; solo en dos unidades asimétricas se pudo identificar una doble entrada. La posibilidad de ingresar a las unidades mediante más de un acceso vuelve más permeables esos espacios.

Comosemencionóal comienzodel trabajo, el estudio de la arquitectura arqueológica permite una aproximación a la idiosincrasia de las poblaciones pretéritas porque las estructuras son el fruto de manufacturas y usos colectivos. Las personas mediante la práctica construyen el espacio y las evidencias recuperadas y estudiadas permiten indagar sobre la organización del comportamiento espacial.

Es por ello que a partir de las evidencias obtenidas de los estudios realizados, se pudieron establecer diferencias espaciales entre los sectores tratados que llevan a concluir que sus habitantes habrían pertenecido a segmentos distintos de una misma sociedad. Las personas del Sector XII se asentaron en la entrada de la Quebrada El Carrizal sobre un relieve más suave y accesible. Hecho por el cual sus habitantes habrían aprovechado las barreras naturales 
propias de la topografía y cimentado todos sus recursos materiales, a la vez que desarrollado y desplegado una serie de tácticas espaciales para ganar control sobre su espacio.

Se concluye la existencia de una heterogeneidad espacial y material de la estructura social del poblado, que se deduce del análisis de los distintos correlatos estudiados. Las diferencias expuestas entre los sectores de cima y ladera generaron una mayor información sobre las personas que los habitaron, además de procesarse novedosos datos sobre un asentamiento escasamente conocido del periodo Intermedio Tardío. En este sentido, se considera que la realización del mismo procedimiento en otros sitios cuya información esté disponible arrojará más luz sobre la diferencia entre sectores o conjuntos arquitectónicos construidos sobre cimas y laderas, que contribuirá a conocer la variabilidad al interior de los sitios y entre los asentamientos tardíos del Noroeste Argentino.

Agradecimientos: A mis compañeras de trabajo Dra. Victoria Coll Moritan y Dra. Paula Villegas, quienes realizaron un vasto relevamiento arquitectónico y fotográfico del sitio El Carmen 1. Al Dr. Javier Nastri por su apoyo y acompañamiento. A Doña Ercilia y Don Manuel por su hospitalidad cada vez que regresábamos a El Carrizal. Finalmente a Sofia Gandini por su lectura afinada y a los anónimos/as revisores/as de este trabajo que permitieron mejorarlo sustancialmente gracias a sus comentarios tan acertados, así como a los/as editores/as de Chungara.

\section{Referencias Citadas}

Acuto, F. 2007. Fragmentación vs. Integración comunal: Repensando el período tardío del Noroeste Argentino. Estudios Atacameños 34:71-90.

Ayán Vila, X.M. 2003. Arquitectura como tecnología de construcción de la realidad social. Arqueología de la Arquitectura 2:17-24.

Bourdieu, P. 1988. La Distinción. Criterios y Bases Sociales del Gusto. Taurus, Madrid.

Cabrera, A.L. 1971. Fitogeografía de la República Argentina. Boletín de la Sociedad Argentina de Botánica 14 (1-2):1-42.

Cantarelli, V. 2017. Desigualdad Social en el Período Tardío: Manifestaciones Espaciales y Materiales del Poblado El Carmen 1, Provincia de Tucumán. Tesis Doctoral. Facultad de Filosofía y Letras, Universidad de Buenos Aires, Buenos Aires.

Cantarelli, V. 2019. Dos quebradas, un poblado. La organización espacial de El Carmen 1, sierra del Cajón, provincia de Tucumán (Argentina). Boletín de Antropología 34 (57):15-44.

Cantarelli, V. y J. Nastri. 2019. El arte rupestre de la quebrada El Carrizal (valle de Santa María, provincia de Tucumán). Actas del XX Congreso Nacional de Arqueología Argentina. 50 años de arqueologías, pp. 150-152. Universidad de Filosofía y Humanidades, Córdoba.

Coll Moritan, V. 2018. Usos y Manejo del Espacio Habitacional durante el Período Intermedio Tardío en el Centro-Oeste del valle de Santa María (Catamarca-Tucumán). Tesis Doctoral. Facultad de Filosofía y Letras, Universidad de Buenos Aires, Buenos Aires.

Coll Moritan, V., V. Cantarelli y J. Nastri 2015. El Carmen 1, un poblado Intermedio Tardío en la Sierra del Cajón (Prov. De Tucumán). Revista del Museo de Antropología de Córdoba 8 (1):105-114.

Criado-Boado, F. 1993. Visibilidad e interpretación del registro arqueológico. Trabajos de Prehistoria 50:36-56.

Criado-Boado, F. 1999. Del Terreno al Espacio: Planteamientos y Perspectivas para la Arqueología del Paisaje. Universidad de Santiago de Compostela, Santiago de Compostela.

DeMarrais, E. 2001. La arqueología del Norte del Valle Calchaquí. En Historia Argentina Prehispánica, editado por E. Berberián y A. Nielsen, pp. 289-346. Editorial Brujas, Córdoba.
Dip, A.B. 2018. La vegetación de El Pichao. En El Pichao nos Habla de El Pichao, editado por A.B. Dip y M.M. Sampietro Vattuone, pp. 26-32. Laboratorio de Geoarqueología, UNT-CONICET, Tucumán.

Earle, T. K. 1987. Chifdoms in archaeology and ethnohistorical perspective. Annual Review of anthropology 16 (1):279-308.

Foster, S.M. 1989. Analysis of spatial patterns in buildings (access analysis) as an insight into social structure: examples from the Scottish Atlantic Iron Age. Antiquity 63 (238):40-50.

Foucault, M. 1983. Vigilar y Castigar: Nacimiento de la Prisión. Siglo XXI, Madrid.

González, A.R. 1954. Las ruinas de Loma Rica y alrededores. Publicaciones Técnicas de Natura 5 (1):75-90.

Hillier, B. y J. Hanson 1984. The Social Logic of Space. Cambridge University Press, Cambridge.

Hodder, I. y C. Orton. 1990. Análisis Espacial en Arqueología. Crítica, Barcelona.

Leibowicz, I. 2007. Espacios de poder en La Huerta, Quebrada de Humahuaca. Estudios Atacameños 34:51-69.

Manzanal, M. 2007. Territorio, poder e instituciones. Una perspectiva crítica sobre la producción del territorio. En Territorios en Construcción. Actores, Tramas y Gobiernos, entre la Cooperación y el Conflicto, editado por M. Manzanal, M. Arzeno y B. Nussbaumer, pp. 15-50. CICCUS, Buenos Aires.

Mañana Borrazás, P. 2003. Arquitectura como percepción. Arqueología de la Arquitectura 2:177-183.

Mañana Borrazás, P. 2005. Análisis de la Percepción aplicado a Espacios Funerarios. Dossier didáctico. Máster en Técnicas de Gestión Integral del Patrimonio Cultural ( ${ }^{a}$ Edición) 2005/2006. CSIC - Instituto de Ciencias del Patrimonio (INCIPIT), Santiago de Compostela.

Mañana Borrazás, P., R. Blanco Rotea y X. Ayán Vila 2002. Arqueotectura 1: Bases Teórico Metodológicas para una Arqueología de la Arquitectura. Universidad de Santiago de Compostela, Santiago de Compostela.

Miller, D. y C. Tilley 1984. Ideology, power and prehistory: an introduction. En Ideology, Power and Prehistory, editado por M. Miller y C. Tilley, pp. 1-15. Cambridge University Press, Cambridge.

Nastri, J. 2001a. La arquitectura aborigen de la piedra y la montaña. (Noroeste argentino, siglos XI a XVII). Anales del Museo de América 9:141-163. 
Nastri, J. 2001b. Interpretando al describir: la arqueología y las categorías del espacio aborigen en el valle de Santa María (noroeste argentino). Revista Española de Antropología Americana 31:31-58

Nielsen, A. 1995. Architectural performance and the reproduction of social power. En Expanding Archaeology, editado por J Skibo, W. Walker y A. Nielsen, pp. 47-66. University of Utah Press, Salt Lake City.

Nielsen, A. 1996. Estructuras y jerarquías de asentamiento en Humahuaca (Jujuy, Argentina) en vísperas de la invasión europea. En XXV Aniversario Museo Arqueológico Dr. Eduardo Casanova, pp. 99-109. Instituto Interdisciplinario de Tilcara, San Salvador de Jujuy.

Nielsen, A. 2001. Evolución social en la Quebrada de Humahuaca (AD 700-1536). En Historia Argentina Prehispánica tomo I, editado por E. Berberían y A. Nielsen, pp. 171-264. Editorial Brujas, Córdoba.

Nielsen,A. 2006. Plazas para los antepasados: Descentralización y poder corporativo en las formaciones políticas preincaicas de los Andes Circumpuneños. Estudios Atacameños 31:63-89.

Nielsen, A. y W.H. Walker. 1999. Conquista ritual y dominación política en el Tawantinsuyu: El caso de Los Amarillos (Jujuy, Argentina). En Sed non Satiata: La Teoría Social en la Arqueología Latinoamericana Contemporánea, editado por A. Zarankin y F. Acuto, pp. 153-169. Ediciones del Tridente, Buenos Aires.

Palma, J. 1998. Curacas y Señores. Instituto Interdisciplinario de Tilcara, San Salvador de Jujuy.

Quiroga, A. 1931. Petrografías y Pictografías de Calchaquí. Universidad Nacional de Tucumán, San Miguel de Tucumán.

Raffino, R. 1988. Poblaciones Indígenas en la Argentina. TEA, Buenos Aires.

Salminici, P. 2015. Simetría y diferenciación espacial. Los edificios de La Alumbrera. Antofagasta de la Sierra. Arqueología 21 (1):89-114.

Sánchez, J. 1998. La Arqueología de la Arquitectura Aplicación de nuevos modelos de análisis a estructuras de la Alta Andalucía en época ibérica. Trabajos de Prehistoria 55 (2):89-109.

Scaro, A. 2019. La configuración espacial de El Pobladito como una aproximación a la organización social preincaica (Quebrada de Humahuaca, Argentina). Antípoda. Revista de Antropología y Arqueología 34:93-118.

Scattolin, M.C., M.F. Bugliani, L. Pereyra Domingorena, L.I. Cortés, M. Lazzari, A.D. Izeta y C.M. Calo 2015. Habitar, circular, hacer. El punto de vista de La Quebrada. En Crónicas Materiales Precolombinas. Arqueología de los Primeros Poblados del Noroeste Argentino, editado por M.A. Korstanje, M. Lazzari, M. Basile, F. Bugliani, V. Lema, L.
Pereyra Domingorena y M. Quesada, pp. 427-464. Sociedad Argentina de Antropología, Buenos Aires.

Sempé, C. 1999. La cultura Belén. Actas de XII Congreso Nacional de Arqueología Argentina III, editado por C. Diez Marín, pp. 250-258. Editorial Universidad Nacional de La Plata, La Plata.

Taboada, C. 2005. Propuesta metodológica para el análisis diacrónico de arquitectura prehispánica y la asignación de significado conductual discriminado. Aplicación en el noroeste argentino. Anales del Museo de América 13:139-172.

Tarragó, M. 1987. Sociedad y sistema de asentamiento en Yocavil. Cuadernos del Instituto Nacional de Antropología 12:179-196.

Tarragó, M. 1995. Desarrollo regional en Yocavil: una estrategia de investigación. Hombre y Desierto 9:225-236.

Tarragó, M. 1999. Las sociedades del Sudeste andino. En Historia General de América Latina, Vol. 1, Las Sociedades Originarias, editado por T. Rojas Rabiela, J.V. Murra, G. Carrera Damas, pp. 465-480. UNESCO-Editorial Trotta, México DF

Tarragó, M. 2000. Chakras y pukaras. Desarrollos sociales tardíos. Los pueblos originarios y la conquista. En Nueva Historia Argentina 1, editado por M. Tarragó, pp. 257-300. Editorial Sudamericana, Buenos Aires.

Vaquer, J.M. 2010. Habitando Cruz Vinto (Norte de Lípez, Bolivia) durante el Periodo de Desarrollos Regionales Tardio (1200-1450 DC.). Una Interpretación desde los Espacios Externos Domésticos. Tesis Doctoral. Facultad de Filosofía y Letras, Universidad de Buenos Aires, Buenos Aires.

Vaquer, J.M. y A. Nielsen 2011. Cruz Vinto desde la superficie: alcances y limitaciones de la sintaxis espacial en un sitio del Período de Desarrollos Regionales Tardío (ca. 1200-1450 d.C.) en el Norte de Lípez, Potosí, Bolivia. Revista Española de Antropología Americana 41 (2):303-326.

Vargas, A., S. Arislur, C. Gentile, M. Taboada y J. Nastri 2016. En torno al alcance de la obra de Adán Quiroga: nuevos registros de los grabados de El Carrizal (Provincia de Tucumán). Actas del I Congreso Nacional de Arte Rupestre, pp. 47-55. Rosario.

Wright, H.T. 1984. Prestate political formations. En On the Evolution of Complex Societies: Essays in Honor of Harry Hoijer, editado por T.K. Earle, pp. 41-77. Undena Press, Malibu.

Wynveldt, F. y B. Balesta 2009. Paisaje sociopolítico y beligerancia en el valle de Hualfín (Catamarca, Argentina). Antípoda 8:143-168.

Wynveldt, F. y B. Balesta 2010. La Loma de Ichanga: visibilidad, defensibilidad y abandono en el valle de Hualfín (Depto. de Belén, Prov. de Catamarca, Argentina). Revista Española de Antropología Americana 40 (1):53-71.

\section{Notas}

${ }^{1}$ Sobre la falda oriental del Valle de Santa María se localiza el sitio arqueológico Loma Rica de Shiquimil (González 1954) sobre un terreno llano y elevado, presenta un trazado urbanístico conglomerado.

${ }^{2}$ No se cuenta con la totalidad de información a la fecha de los Sectores IV, X y XIV, pero se estima que poseen escasas estructuras en relación al resto de los sectores (I:5, II:35, III:9, V:23, VII:13, VIII:2, IX:3, XI:6, XIII:64, XIV:5 y XV:30).
${ }^{3}$ Se define como unidad compuesta al conjunto de recintos asociados que comparten muros (Nastri 2001a, 2001b).

${ }^{4}$ De acuerdo con el área de superficie de las estructuras se clasificaron en cinco categorías de tamaño: A (menores de $\left.5 \mathrm{~m}^{2}\right)$, $\left(5,01\right.$ a $\left.10 \mathrm{~m}^{2}\right), \mathrm{C}\left(10,01\right.$ a $\left.20 \mathrm{~m}^{2}\right), \mathrm{D}\left(20,01\right.$ a $\left.40 \mathrm{~m}^{2}\right)$ y E (mayores a $\left.40 \mathrm{~m}^{2}\right)$ (Coll Moritan et al. 2015). 